\title{
Revisitando a controvérsia sobre a transmissibilidade intercultural do conhecimento administrativo
}

\author{
Revisiting the controversy on intercultural transferability of administrative knowledge
}

Paulo Roberto Motta ${ }^{1}$

\begin{abstract}
Resumo
O objetivo deste trabalho é apresentar uma nova perspectiva da controvérsia sobre a transmissibilidade do saber administrativo, normalmente ofuscada pela maior atenção contemporânea ao contingencialismo cultural. A maior interdependência entre as nações gerou novos desafios do saber, necessidades de desenvolvimento e expectativas sobre a oportunidade de novas ideias. A aquisição de hábitos semelhantes fez o contexto mundial parecer cada vez mais uma grande arena de compartilhamento de culturas. A preocupação com a transmissibilidade se acentuou em função do crescimento mais rápido de nações consideradas menos avançadas, assim como das expectativas de transformação das práticas gerenciais. Presume-se ser a transferência do saber um fator relevante para a modernização das instituições públicas e privadas. Neste trabalho se contrapõem duas correntes de pensamento: a primeira assume o conhecimento administrativo como intransferível a outro meio cultural; a segunda o assume como transferível e necessário a outro meio cultural. Por meio da explicitação de novos argumentos teóricos e exemplos de vínculos com a prática gerencial internacional, ele é concluído com várias proposições sobre a transmissibilidade do saber administrativo.
\end{abstract}

Palavras-chave: Transmissibilidade do saber. Saber administrativo. Conhecimento intercultural.

\begin{abstract}
This paper aims to introduce a new perspective on the controversy about the transferability of administrative knowledge, usually overshadowed by greater contemporary attention to cultural contingentialism. Increased interdependence between nations generated new challenges to knowledge, development needs, and expectations about the opportunity for new ideas. The acquisition of similar habits made the global context increasingly seem a large arena of cultural sharing. The concern about transferability has grown due to faster growth of nations regarded as less advanced, as well as expectations to change management practices. It is assumed that knowledge transfer is a relevant factor for the modernization of public and private institutions. Two currents of thought are opposed in this paper: the first regards administrative knowledge as untransferable to another cultural environment; the second regards it as transferable and needed by another cultural environment. By explaining new theoretical arguments and examples of links to the international managerial practice, it is concluded with many propositions on the transferability of administrative knowledge.
\end{abstract}

Keywords: Transferability of knowledge. Administrative knowledge. Intercultural knowledge.

Artigo submetido em 30 de outubro de 2012 e aceito para publicação em 13 de maio de 2014

DOI: http://dx.doi.org/10.1590/1679-3951745

1 Ph.D. e M.A. pela University of North Carolina; Professor Titular da FGV/EBAPE - Escola Brasileira de Administração Pública e de Empresas. Endereço: Praia de Botafogo, 190 - 5 andar - Botafogo, CEP 22250-900, Rio de Janeiro - RJ, Brasil. E-mail: paulo.motta@fgv.br. 


\section{Introdução: Impactos e Necessidade}

A eliminação de fronteiras econômicas e a maior interdependência entre as nações provocaram transformações expressivas nas últimas décadas. Cada vez mais as organizações públicas e privadas veem-se inseridas nas cadeias produtivas mundiais com uma maior variedade de interligações internacionais ou interculturais.

Acentua-se a substituição dos espaços nacionais de concorrência pelos internacionais e reacende-se a consciência mundial sobre desequilíbrios e atrasos econômicos. Consequentemente, aumenta a expectativa sobre a oportunidade e a necessidade de novas ideias. Pressões para aprimorar o desempenho geram novos desafios do saber e do fazer.

No mundo da complexidade e da interdependência, nenhuma organização ou mesmo um país pode enfrentar sozinho os problemas e desafios contemporâneos (GULRAJANI e MOLONEY, 2012). As novas redes sugerem propostas de absorção de novos conhecimentos e a revitalização da capacidade e com uma maior variedade de interligações internacionais ou interculturais das responsabilidades administrativas, bem como as relações das empresas e do governo com a sociedade (FARAZMAND, 2009; ABONYI e VAN SLYKE, 2010; JREISAT, 2011).

Ao responder aos desafios da mundialização, as instituições públicas, as grandes empresas e as entidades não governamentais inserem-se aos poucos em um novo contexto de múltiplos contatos interculturais. Buscam novas práticas gerenciais, inspiradas em outros países, sobretudo nos mais avançados e nos que chamam atenção pelo seu progresso recente. Assim, concorrem para emergir métodos similares de decisão e de ação (BERGER e HUNTINGTON, 2002). Hipóteses sobre o contingencialismo cultural tornam-se vulneráveis e favorecem as proposições sobre a transmissibilidade intercultural de conhecimentos gerenciais.

A aquisição de hábitos semelhantes faz o contexto mundial parecer cada vez mais uma grande arena de compartilhamento de culturas. Mesmo diante da permanência das singularidades culturais, a convergência tem progredido e estilos de vida similares invadem a maioria dos países.

Até as nações mais distantes já se assemelham entre si e dispensam expressões da cultura local. As grandes cidades se tornam um ambiente da diversidade e do multiculturalismo. A imigração massiva nas últimas décadas tem concorrido para o compartilhamento de novos hábitos e valores de vida. As formas de comunicação se tornam iguais: nas transações internacionais, a língua inglesa tornou-se o principal veículo, trazendo consigo as mesmas características culturais dos países que a têm como vernácula (GEOFFEROY, 2005; WIERZBICKA, 2003).

A função administrativa adquiriu uma perspectiva planetária: o desempenho, mesmo em pequenas empresas ou unidades menores de governo, passa a depender da capacidade gerencial de lidar eficientemente com ações de natureza intercultural. Aguça-se a prática do benchmarking, na tentativa de minimizar problemas de competitividade de mercado e de hábitos administrativos. Concorre, assim, para maior similaridade não só nas formas de refletir e de agir, mas, também, nos processos de trabalho e nos controles de gestão. Vale notar, ainda, a influência das modernas tecnologias de informação e de comunicação na imposição de novas atitudes e práticas de trabalho acentuadamente semelhantes em todos os países. Ademais, várias e crescentes regulamentações supranacionais projetam uniformidades nas organizações de trabalho, tanto públicas como privadas. Os sistemas administrativos já não constituem fatores de grande diferenciação entre países.

Há uma convergência cultural em progresso. Seria ingênuo pensar que somente as práticas gerenciais seguiriam caminhos diferentes.

A produção do saber gerencial tornou-se mais universal e baseada nas mesmas premissas, métodos e temas típicos valorizados nos meios acadêmicos. Por ser cada vez mais proclamado como fator de progresso, o conhecimento administrativo tem atraído mais atenção sobre seu uso e sobre sua transmissibilidade 
intercultural. Mesmo sendo parte da expressão de identidade e cultura, a prática do saber administrativo tem se assemelhado entre países.

A globalização reacendeu, nas nações consideradas menos avançadas, a possibilidade de um crescimento mais rápido. Adicionalmente, acentuou-se a crença no desenvolvimento da capacidade gerencial dessas nações. A expectativa sempre foi de conhecimentos capazes de explicar e transformar a prática de maneira significativa. A inspiração maior sempre foi o saber e a experiência dos países mais avançados. A lógica mais simples e factível seria a de seguir o já experimentado em outros contextos, ou seja, a trilha dos pioneiros: construir instituições e regras similares às dos mais desenvolvidos.

Anteriormente à perspectiva da globalização, havia uma maior preocupação com as imposições do conhecimento gerencial como parte da distribuição de poder entre países e forte influência dos mais desenvolvidos. Países emergentes e o progresso asiático ampliaram a produção e a consciência das potencialidades do conhecimento gerencial, sobressaindo as características de produtividade e de ação inovadora em maior número de regiões.

No entanto, a perspectiva tradicional de análise continuou a ser enfatizada em algumas análises relacionadas ao conhecimento gerencial (IBARRA-COLADO, 2011). Modelos ainda centrados nas perspectivas tradicionais conservaram as premissas excessivamente genéricas e culturalmente distorcidas por verem universalidade e uniformidade do conhecimento somente na cultura produtora e diversidade somente na cultura receptora.

Em decorrência, propaga-se a lógica de imposição generalizada, como se os países mais avançados possuíssem um único modelo de gestão a ser usado para eliminar a diversidade cultural de outros.

O propósito deste trabalho é apresentaruma perspectiva sobre a transmissibilidade do saber administrativo normalmente ofuscada pelas atenções contemporâneas como o contingencialismo cultural. O foco principal está na transmissibilidade de conhecimentos e práticas gerenciais entre culturas produtoras e receptoras. Presume-se ser essa transferência um fator relevante e uma prática cada vez mais intensificada para a modernização administrativa. Não se desconsideram os estudos sobre contingências culturais, mas se vê a cultura menos como um fator contingencial absoluto e mais como uma variável adicional nas perspectivas teóricas e práticas sobre a gestão.

Por meio da explicitação de novos argumentos teóricos e exemplos de vínculos com a prática gerencial internacional se constrói um conjunto de proposições valorizadoras da transmissibilidade do saber administrativo. Os argumentos são baseados na literatura internacional de foco intercultural. No desenvolvimento do trabalho, contrapõem-se duas correntes de pensamento. A primeira assume o conhecimento administrativo como transferível a outro meio cultural por estar contaminado por valores culturais dos produtores. A segunda, valorizada neste trabalho, presume o saber administrativo moderno, produzido e praticado em outros contextos culturais, como transferível e necessário a outro meio cultural.

Transferir conhecimentos significa a inserção proveitosa de novas competências e habilidades em uma organização ou em uma de suas unidades (BRESMAN, BIRKINSHAW e NOBEL, 1999; ZANDER, 1991). Privilegia as diferenças mais vantajosas de outras organizações ou contextos culturais; inclui o aprendizado e o desenvolvimento por compartilhamento de competências (BJÖRKMAN, STAHL e VAARA, 2007).

O conhecimento administrativo, os arquétipos culturais e a forma de racionalidade presentes nos países mais avançados - maiores produtores de saber - constituem-se, predominantemente, nos padrões centrais para o desenvolvimento gerencial. A maioria dos países, sobretudo aqueles em desenvolvimento - maiores receptores de saber -, toma esses padrões como referência para melhorar suas competências e habilidades. $\mathrm{Na}$ realidade, em todas as áreas de conhecimento, há entre os mais avançados a expectativa sobre inovações, descobertas e invenções. Assim, pode-se identificar uma origem geográfica, econômica e nacional na definição dos conceitos de cultura produtora e de cultura receptora de conhecimentos. 
A inserção de novas práticas gerenciais ocorre, em diferentes culturas, sempre com a premissa de gerar melhores resultados, similares aos produzidos nos países de origem. No entanto, a transferência de conhecimentos pode ser afetada não só pelos valores da origem nacional do conhecimento como por outros valores da cultura receptora (DUANMUI e FAI, 2007). Além disso, o novo conhecimento pode ser desconsiderado pela dificuldade de percepção de seu valor em função de diferenças acentuadas em relação à cultura nacional produtora (JAVIDAN, STAHL, BRODBECK et al., 2005; SIMONIN, 1999). Logo, são desenvolvidas correntes de pensamento que se contrapõem entre a possibilidade e a impossibilidade de transferir interculturalmente conhecimentos e práticas gerenciais.

Normalmente, os defensores da transmissibilidade a julgam desejável e necessária. Outros, por assumir a impossibilidade, pouco se referem a aspectos de intencionalidade da inserção. Essas correntes se contrapõem por meio de duas proposições básicas - sintetizadas no Quadro 1.

\section{Quadro 1}

\section{Proposições básicas sobre a transmissibilidade e a intransmissibilidade intercultural do conhecimento} gerencial

\begin{tabular}{|l|l|}
\hline $\begin{array}{l}\text { A intransmissibilidade do conhecimento e a } \\
\text { impossibilidade de gerenciar a cultura }\end{array}$ & $\begin{array}{l}\text { A transmissibilidade do conhecimento e a } \\
\text { importância de gerenciar a cultura }\end{array}$ \\
\hline $\begin{array}{l}\text { O conhecimento gerencial é contaminado } \\
\text { culturalmente e, por definição, não é } \\
\text { transmissível em sua totalidade. }\end{array}$ & $\begin{array}{l}\text { A cultura é aprendida e, portanto, o } \\
\text { conhecimento gerencial pode ser transmitido, } \\
\text { ainda que adaptado às condições da cultura } \\
\text { receptora. }\end{array}$ \\
\hline $\begin{array}{l}\text { A cultura organizacional é uma reprodução da } \\
\text { cultura nacional e não pode contrapor-se a ela. }\end{array}$ & $\begin{array}{l}\text { A cultura organizacional não é um reflexo puro } \\
\text { da cultura nacional e, portanto, pode } \\
\text { contrapor-se a ela. }\end{array}$ \\
\hline $\begin{array}{l}\text { A cultura não é uma variável manejável e, } \\
\text { portanto, não há por que atentar a aspectos de } \\
\text { transmissibilidade - culturais nacionais ou } \\
\text { organizacionais. }\end{array}$ & $\begin{array}{l}\text { A cultura é manejável, não importa se } \\
\text { independente ou dependente da cultura } \\
\text { nacional. }\end{array}$ \\
\hline
\end{tabular}

Fonte: elaborado pelo autor.

Proposição 1: A intransmissibilidade do conhecimento administrativo e a impossibilidade de gerenciar a cultura

Por estar contaminado pelos valores culturais dos produtores, o conhecimento administrativo não pode ser transferido. A racionalidade e as tecnologias administrativas só podem ser transferidas a outros contextos se precedidas de significativas mudanças culturais e sociais. Para essa corrente de pensamento, a cultura não é uma variável administrável e, assim, não há por que atentar a aspectos de transmissibilidade da cultura, tanto nacional como organizacional.

A cultura nacional fornece os padrões sociais pelos quais as pessoas moldam suas atitudes e seus comportamentos, inclusive os administrativos, e torna previsíveis suas visões de mundo (BOYLE e COUGHLIN, 1994). Proclama-se, portanto, a cultura como uma variável antecedente, independente e explicadora das conquistas e atitudes gerenciais. A cultura do país prevalece e a transmissibilidade de 
conhecimentos gerenciais só é possível dentro dessa cultura. Vê-se a cultura organizacional como uma reprodução da cultura nacional e não pode contrapor-se a ela.

A perspectiva da dependência da gestão em relação às variações nacionais deixa implícita a dificuldade da transferência de saberes. Proclamações sobre cultura nacional como condicionante e até obstáculo à maior eficiência gerencial têm sido comuns e enfáticas nos últimos anos. Comparações sobre a gerência procuram mostrar variações de atitudes e de comportamentos em função da origem nacional de dirigentes (cf. BERGER e HUNTINGTON, 2002; HOFSTEDE, 1980; 1983; 1991; HOFSTEDE, HOFSTEDE e MINKOV, 2010; THOMAS, 2002; HAMPDEN-TURNER e TROPENAARS, 1998; MORAN, HARRIS e MORAN, 2010; HOUSE, HANGES, JAVIDAN et al., 2004).

Ao ressaltar características singulares, os atores minimizam semelhanças e desconhecem as interferências dinâmicas nas construções culturais. A visão estática da cultura, com as pessoas condicionadas ou vítimas de padrões coletivos, foi lançada pioneiramente por Hofstede (1991) e seus seguidores: eles veem a cultura como um software coletivo na mente das pessoas e a identidade nacional como um elemento meramente passivo inserido em um modelo cultural.

Por intransmissibilidade, novos valores gerenciais são impossíveis e, no máximo, representam uma tentativa de impor práticas alienígenas. A eficiência gerencial só será alcançada após a produção e a inserção endógenas de conhecimentos e de racionalidades e, assim, trata-se de uma consequência e não causa do progresso.

Presumem-se os valores culturais como profundamente inseridos no subconsciente das pessoas, porém, mesmo se fosse possível alguma mudança cultural, não seria recomendável, por dilemas éticos (OGBOR, 2001; WATSON, 2002; WILLMOTT, 1993). Como parte integrante da organização, a cultura não pode ser manipulada, e, assim, há a impossibilidade de transferência ou de interferência na cultura organizacional (ANTHONY, 1990; KNIGHTS e WILLMOTT, 1987; LEGGE, 1994; WILLMOTT, 1993).

Assume-se, de modo geral, ser a cultura organizacional um reflexo claro da cultura nacional. Em princípio, as diferenças nas culturas nacionais têm impactos mais fortes na transferência de conhecimento do que fatores da cultura organizacional. Quando há diferenças significativas entre a cultura nacional e a organizacional, pode haver maior dificuldade para identificar, transferir e implementar conhecimentos potencialmente úteis (SIRMON e LANE, 2004).

Ao julgar impossível o manejo da cultura organizacional, questiona-se a capacidade dos gerentes para compreender e controlar os valores básicos dos funcionários. Por se presumir como impossível a mudança cultural planejada, os proponentes dessa corrente não fazem sugestões práticas e não reconhecem na modernização gerencial uma das formas de ruptura com tradições preservadoras ou de promoção do progresso social, econômico e político.

Qualquer ação de modernização gerencial seria produto de inovações criativas internas após mudanças na própria sociedade. Para os praticantes da gerência, cria-se uma paralisia inócua em termos das ações atuais. Nada a fazer, a não ser simplesmente esperar. Nesse sentido, as opções em relação à moderna tecnologia administrativa são muito reduzidas e, por isso, na perspectiva comparativa, essa corrente progrediu pouco.

Entretanto, cada vez mais, verificou-se ser a racionalidade administrativa moderna necessária para uma transição social e econômica, sobretudo quando os valores e práticas tradicionais já não são capazes de satisfazer as demandas da sociedade.

Assim, a ideia da transmissibilidade ganhou espaço e esforço na gestão do progresso. 


\section{Proposição 2: A transmissibilidade do conhecimento e a importância de gerenciar a cultura}

Presume-se o conhecimento administrativo moderno, produzido e praticado em outros contextos culturais, como transferível e necessário a outro meio cultural. A eficiência gerencial depende da inserção de práticas modernas e é uma precondição para o desenvolvimento nacional e organizacional. Essa proposição é baseada não em provas sobre uma relação causal, mas em descrições de práticas administrativas observadas nos países mais avançados. Assim, instrumentos modernos de gestão e formação de gestores tornaram-se um imperativo para o progresso. Assume-se explicitamente a transmissibilidade da racionalidade administrativa moderna presente nos países mais desenvolvidos.

Essa premissa parece revigorada nas perspectivas contemporâneas. Por exemplo, novos estudos comparativos reativam a necessidade de uma administração forte com conhecimentos modernos para conduzir o desenvolvimento. Questiona-se novamente o melhor modo de adquirir e transferir conhecimentos (ZHANG, 2009).

A perspectiva da transmissibilidade vem imbuída da crença sobre a importância de gerenciar a cultura em nível organizacional. Para essa corrente de pensamento, a cultura organizacional não é um reflexo puro da cultura nacional, podendo, inclusive, contrapor-se a ela. Como outras, a cultura é apenas uma variável a ser manejada, não importa se independente ou dependente da cultura nacional.

Os fatores nacionais podem ser ajustados, gerenciáveis, e criar uma nova cultura mais voltada à modernidade. Processos de trabalho, instrumentos gerenciais e formas comportamentais podem ser introduzidos em outras culturas, independente de considerações sobre as origens nacionais das ideias. Assim, a inserção de uma gerência mais moderna é não só viável, mas, também, necessária ao progresso.

Ao se procurar entender o grau de influência de fatores culturais sobre atitudes e comportamentos administrativos - como, ainda, sobre os resultados organizacionais -, aprofundam-se os questionamentos sobre a validade da cultura nacional (GERHART, 2009; GERHART e FANG, 2005). A forma de apresentar generalizações sobre a cultura nacional também aparece como excessivamente determinística e capaz de ofuscar culturas organizacionais e grupais.

De um lado se presumem as diferenças entre países como substancialmente menores do que diferenças culturais dentro do país (GERHART, 2009). Tornam-se pouco confiáveis as generalizações sobre a cultura nacional. Possivelmente, há necessidade de avançar no conceito tradicional de cultura.

As hipóteses tradicionais são, normalmente, oriundas de definições de cultura como compartilhamento de identidades, valores e práticas e significados e, assim, tendem a ressaltar ou mesmo exagerar diferenças entre culturas nacionais (GERHART, 2009). Por exemplo, se a cultura for definida como referências compartilhadas sobre a maneira de organizar a vida social, pode emergir uma visão de maior unidade cultural. Não se trata de negar diferenças, mas de sublinhar o fato de haver maiores semelhanças.

Também há evidências, cada vez mais fortes, para contestar a cultura nacional como restritiva à prática gerencial. Variações das culturas organizacionais dentro do mesmo país são consideráveis, mas não necessariamente isomórficas com a cultura nacional.

A maioria das organizações possui uma cultura não isomórfica com a cultura nacional (GERHART, 2009).

A cultura nacional explica apenas $6 \%$ da variação na cultura organizacional e, mais especificamente, com base em dados de 208 organizações, mostra ser de apenas $23 \%$ a variância em práticas culturais dependentes de cultura nacional (HOUSE, HANGES, JAVIDAN et al., 2004). 
Há, ainda, forças de similaridade organizacional ou do modo de produção que direcionam a cultura organizacional para o mesmo sentido. Um estudo sobre três nações - Estados Unidos, Brasil e Índia - revela uma forte tendência à similaridade, apesar de algumas diferenças significativas (NELSON e GOPALAN, 2003). Entre dirigentes, os fatores de progresso são explicados muito mais em função de decisões e ações organizacionais do que de fatores favoráveis de uma cultura nacional. Por exemplo, quando questionados sobre o êxito e a cultura da empresa, os dirigentes tendem a falar de assuntos comuns às organizações, como missão, valores e visão (HOLDEN, 2001).

Verifica-se uma ênfase excessiva na cultura nacional, em detrimento de outras variáveis econômicas sociais e políticas (YEGANEH e SU, 2006). Na ausência de outras explicações, atribui-se valor explicativo à cultura (SCHAFFER e RIORDAN, 2003; SWANN JR., POLZER, SEYLE et al., 2004). Portanto, há a necessidade de buscar outros mediadores nas explicações culturais relativas à gerência (HARZING, 2001; KIRKMAN, LOWE, GIBSON et al., 2006).

O conhecimento gerencial de uma organização é o acervo de sua experiência, seus valores e suas boas práticas. Estes provêm de um processo dinâmico, contínuo e complexo, fundamentado em um pragmatismo idealista, ou seja, que tem a expectativa de utilidade prática (NONAKA, 2007). Portanto, tal conhecimento é construído em um contexto organizacional específico e, naturalmente, incorporado à própria cultura da organização. O fator distintivo é que, independente de considerações interculturais, ele passou a ser visto como o mais importante fator para a competitividade (WANG, LIU, LI et al., 2009; BUCKLEY e CARTER, 1999). Assim, existem fundamentos razoáveis para se notar o desenvolvimento de uma cultura organizacional, com variações distintas da cultura nacional. Portanto, é possível aceitar fatores próprios da cultura organizacional como mais limitadores da utilidade do novo conhecimento do que os da cultura nacional (SIRMON e LANE, 2004).

É notável o incentivo para empresas privadas e instituições públicas buscarem novos padrões gerenciais em países mais avançados. Já não se assume irrestritamente a novidade como afinada unicamente com uma cultura nacional. O resultado de importar novas ideias pode ser positivo tanto empresarialmente como nacionalmente. Práticas inovadoras, atípicas da cultura local, não constituem um obstáculo, como é normalmente sugerido (GERHART, 2009). Relatos sobre dificuldades e conflitos em meios multiculturais podem reforçar a crença sobre a impossibilidade de importar ideias inovadoras. Torna-se fácil presumir métodos atípicos da cultura local como causadores de ineficiências. Porém, também é difícil definir, em meios administrativos, conflitos como essencialmente culturais.

Modelos clássicos de análise administrativa, fundamentados em diferenciações de culturas nacionais, já sofrem algumas restrições pela sua inadequação. Há dúvidas e necessidades de explorar melhor a verdadeira influência dos fatores da cultura nacional. Por centrar a atenção unicamente em fatores culturais, pesquisas tradicionais deixam de lado muitas outras variáveis determinantes dos comportamentos gerenciais presentes nos contextos sociais (KIRKMAN, LOWE, GIBSON et al., 2006).

Transferir práticas comprovadamente bem-sucedidas parece algo normal e promissor. Recusá-las por critérios genéricos de inadaptação cultural aparece como um rompimento com o próprio êxito. Seria insensato não usufruir da capacidade gerencial criada por outros.

Ao reacender a perspectiva sobre a transmissibilidade intercultural do saber administrativo, é possível notar instâncias importantes que a própria literatura dos países mais produtores sugere sobre o tema. O Quadro 2 resume algumas dessas proposições. 


\section{Quadro 2}

\section{Proposições sobre a transmissibilidade intercultural do saber administrativo}

a) A cultura gerencial é dinâmica e aprendida também por interpretações simbólicas, práticas de vida e de gestão.

b) O desenvolvimento depende da introdução de práticas gerenciais consagradas como exitosas.

c) A cultura gerencial é menos um espaço físico e mais uma arena social na qual as pessoas fazem escolhas sobre suas vidas e relações com outros.

d) Diferenças culturais na prática gerencial podem constituir discriminação entre equipes de trabalho ou pessoas.

e) Na transmissão intercultural há sempre uma hierarquização de práticas culturais para satisfazer padrões de produtividade.

f) A ênfase na contaminação cultural pode desvalorizar a possibilidade de aprendizado e desenvolvimento além dos próprios criadores.

g) Há uma maior atenção a fatores universais para explicar o desempenho organizacional.

h) A transmissibilidade do conhecimento é um processo adaptativo e criativo.

Fonte: elaborado pelo autor.

A cultura gerencial é dinâmica e aprendida também por interpretações simbólicas, práticas de vida e de gestão

Por ser aprendida por meio de processos diversos de socialização, a cultura, sobretudo a gerencial, é dinâmica: além de recebida do passado, por meio de aprendizado, tradições, palavras e interpretações simbólicas, também é fruto de uma compreensão cotidiana das práticas de vida e de gestão. Dimensões culturais na gerência também são socialmente construídas.

A gerência é essencialmente uma prática de inovação, resistência e adaptação. Há possibilidades e opções. Nem todas as empresas optam igualmente pelas mesmas práticas: elas optam por alguns critérios. Suas práticas gerenciais são testadas, verificadas e adaptadas, e, assim, elas escolhem seus caminhos, rompendo com tradições, modificando hábitos culturais e inserindo a novidade. Na dimensão cultural, importa menos a forma individual de transferência e mais a possibilidade de absorção coletiva.

Assim, a transferência de novos saberes gerenciais ocorre em nível de aprendizagem organizacional (HUBER, 1991, 2001). Consequentemente, sempre há a intenção estratégica de incorporar um novo saber envolvendo a globalidade de dimensões organizacionais.

Por isso, a eficácia da transferência depende não só da motivação para adquirir e assimilar (MINBAEVA, PEDERSEN, BJÖRKMAN et al., 2003), mas, também, da habilidade gerencial para identificar, compartilhar, coletivizar e intercambiar o novo saber (GUPTA e GOVINDARAJAN, 2000; SZULANSKI, 1996). 
Por ser um aprendizado cultural, a intenção estratégica depende de uma disseminação e coletivização das ideias novas. Esse processo pode ser formalmente planejado, mas o próprio contato com o inusitado possibilita a incorporação de novas visões e valores sobre a realidade. Se cultura é conhecimento, qualquer interação cultural envolve troca de conhecimentos (HOLDEN, 2002). Em princípio, toda forma de contato intercultural possibilita a transmissão de conhecimento, inclusive o aprendido por meio das relações sociais e gerenciais.

O valor estratégico do conhecimento gerencial está não na sua existência, mas, sim, na sua aplicação prática (SANTOSH e MUTHIAH, 2012). As repercussões na produtividade pela disseminação cultural de conhecimentos gerenciais já é bastante revista e documentada (BUCKLEY, CLEGG, WANG et al., 2002; AITKEN e HARRISON, 1999) e revela um acervo valioso de ideias para ações organizacionais em diferentes contextos culturais. São muitos os exemplos de transferência bem-sucedida (CHILD, FAULKNER, PITKETHLY et al., 2000; BJÖRKMAN, STAHL e VAARA, 2007; GAMBLE, 2003; 2010),sobretudo de empresas multinacionais de suas matrizes para as subsidiárias ou associadas nos contextos locais, verificando-se, também, o inverso, embora em menor escala (FU, 2012).

\section{O desenvolvimento depende da introdução de práticas gerenciais consagradas como exitosas}

Por ter se tornado mais convergente e competitivo, o mundo produziu práticas gerenciais, públicas e privadas, mais semelhantes e imitação mais rápida de experiências exitosas.

A visão do conhecimento como um recurso estratégico na organização moderna (NONAKA, 2007; NONAKA e TAKEUCHI, 2008; HAMEL e PHRAHALAD, 1991; 2005) incentivou cada vez mais sua transferência intercultural para o desenvolvimento organizacional (LIU, 2012).

A perspectiva da transmissibilidade ganha reforço com o surgimento de mais evidências para ressaltar o valor do conhecimento como recurso estratégico no progresso empresarial e na inserção inovadora das organizações em seu contexto comunitário e de mercado (ARGOTE e INGRAM, 2000; HENDRIKS, 1999; MCADAM e MCCREEDY, 1999).

A transferência eficaz de instrumentos gerenciais já explica as diferenças de produtividade entre países e compreende igualmente várias áreas e técnicas de trabalho, independente dos instrumentos gerenciais utilizados, como gestão estratégica, processos e recursos humanos (BLOOM e VAN REENEN, 2007; BARTLETT, LAWLER, BAE et al., 2002; HUSELID, 1995; BROX e FADER, 2002). Essa prática internacional repetitiva de incorporar técnicas e métodos similares sobre as diversas áreas do conhecimento administrativo deixa menos dúvidas sobre a transmissibilidade e a modernidade gerencial como fator de desenvolvimento.

As incertezas sobre diferenças culturais parecem ter se dissipado não só quando se verifica a internacionalização dos programas de ensino, mas, também, quando se observa o deslocamento de milhares de estudantes que buscam expandir sua formação gerencial em outros países. Propósitos e expectativas comuns transcendem as fronteiras nacionais. Teorias e práticas de gestão, originárias dos países mais desenvolvidos, incluindo a formação, espalharam-se pelo planeta como uma forma universalmente útil.

Nos países emergentes, por exemplo, já se revela uma ruptura com padrões tradicionalmente estabelecidos. Mesmo reconhecendo as diferenças culturais, parece haver uma nova crença na potencialidade desses novos conhecimentos. Seria insensato não usufruir da capacidade gerencial criada por outros.

Já se reconhecem, no senso comum, as novidades em bens e serviços como produto de novas conquistas gerenciais. Novos saberes gerenciais, mais universais e mais facilmente adaptáveis, já fazem parte do novo cotidiano de desenvolvimento. 
A cultura gerencial é menos um espaço físico e mais uma arena social na qual as pessoas fazem escolhas sobre suas vidas e relações com outros

A cultura gerencial é menos um lócus ou espaço físico e mais uma arena social na qual as pessoas fazem escolhas para justificar suas vidas, seus hábitos culturais e relações com outros (COYLE e ELLIS, 1994). Nesse espaço há uma produção interativa de significados simbólicos, capazes de moldar a identidade individual em seu pertencimento nacional ou organizacional. Padrões gerenciais, antes de ser determinados por contingências culturais, também são escolhas individuais (AILON-SOUDAY e KUNDA, 2003). Na verdade, a aculturação gerencial é uma construção social na qual os participantes não são passivos, a aceitar acriticamente a incorporação de novos valores e práticas (WILDAVSKY, 1987; DOUGLAS, 1970; 1992), havendo, inclusive, espaço para as pessoas escolherem a própria cultura (TIPTON, 2009).

Portanto, a organização do trabalho é um espaço de reconstrução cultural contínua capaz não só de mudar a vida das pessoas, mas, ainda, de ter impacto significativo na cultura de um país. Administrar o progresso significa também uma busca coletiva de novos significados e interpretações das pessoas, sobre si próprias e suas organizações. A transformação cultural do trabalho possibilita a reconstrução de relações sociais com a maior consciência e sensibilidade sobre as condições culturais de um mundo em mudança.

Diferenças culturais na prática gerencial podem constituir discriminação entre equipes de trabalho ou pessoas

Retratos de diferenças culturais em práticas gerenciais deixam explícito um incentivo a acentuar a percepção de desigualdades entre equipes de trabalho e funcionários, minimizando as semelhanças capazes de integrar as pessoas. A noção de diferença é construída por categorias gerenciais, facilmente identificáveis umas como formas superiores ou mais avançadas e outras como ainda dependentes de inovação. Comunidades culturais procuram guardar e ressaltar certas diferenças, como uma maneira de preservar suas identidades.

A identidade social inserida na cultura nacional pode emergir como uma fonte de contraposição e mesmo de confrontação nas relações administrativas de natureza intercultural (CORNELISSEN, HASLAM, BALMER et al., 2007; HOGG e TERRY, 2001). Na relação entre membros de uma cultura - transmissora e receptora de valores - sempre há incertezas, ambiguidades e possibilidades de conflito (TERRY, 2001; VAN KNIPPENBERG e VAN LEEUWEN, 2001).

Quando se ressaltam as diferenças e valores contraditórios em uma estrutura organizacional de poder, aguçase a potencialidade de conflitos (BUONO e BOWDITCH, 1989; VAN KNIPPENBERG e VAN LEEUWEN, 2001; EMPSON, 2001) e identificam-se as diferenças culturais como causadoras de tensões e confrontações (JEHN, 1997) e de obstáculos à construção de uma interação mais autêntica e confiável (SIRMON e LANE, 2004).

No entanto, as organizações já são repletas de conflitos e de baixos níveis de confiança, independente da ocorrência de contatos interculturais. Assim, não é fácil constatar se motivos simplesmente culturais são causa de conflitos, pois é possível que a dificuldade de consenso sobre decisões e ações esteja destacada do contato intercultural.

A inserção de um novo saber faz necessária a coletivização de ideias novas, em que permeia a variedade de percepções sobre adequação e possibilidade do inusitado. Por compartilhamento de novos valores se constrói gradualmente um novo ambiente cultural de harmonia e igualdade entre seus membros (DAMERON e JOFFRE, 2005). Quando se acentuam as similaridades entre grupos culturais, cria-se uma identificação em valores favorecedores de nova capacidade gerencial. 
Há muitas similaridades a ser observadas e presumidas na gerência, inclusive por valores de classe social. As classes sociais superiores, nas quais se recrutam e interagem os dirigentes e gerentes, são mais semelhantes em atitudes e comportamentos entre países. Gerentes e administradores internacionais mostram o mundo gerencial mais similar social, política e culturalmente (HUNTER e YATES, 2002).

Também são pouco convincentes os argumentos de que dirigentes e gerentes, por viver mais isolados e no topo das organizações, são pouco expostos à variedade da cultura local, pois não se adaptam às condições locais - isolando-se e vivendo em bolhas (HUNTER e YATES, 2002). A vida social em bolhas é possível, e classes sociais mais elevadas se distinguem e adquirem padrões singulares de vida em muitos países. Mas o isolamento é impossível na execução de tarefas gerenciais. Por ser essencialmente interativa, personalizada e humana, a gerência não pode ser executada tão impessoalmente.

\section{Na transmissão intercultural há sempre uma hierarquização de práticas culturais para satisfazer padrões de produtividade}

Por ocorrer em uma estrutura organizacional, na transmissão intercultural de conhecimentos há elementos de poder que podem influenciar a programação coletiva em relação à introdução de novidades.

As organizações são dependentes de sua história e de valores culturais; assim, têm dificuldade para romper com o conhecido e o experimentado. Tal como outros processos de inovação, a inserção intercultural de novas práticas gerenciais ocorre em meio a aderências, ou adesões, e resistências.

A intenção da mudança aguça as contradições naturais: valores, tradições e interesses podem ser rompidos, gerando apoios e, em contraposição, resistências. Como danifica práticas usuais, a inovação acaba por gerar receios sobre a possibilidade de êxito de novos métodos. Se a normalidade organizacional já exige um grande esforço de coordenação, a inserção do inusitado pode fazer emergir novos conflitos, inclusive com a percepção de contraposições culturais.

Por isso a mudança de natureza cultural exige mais preparo para um novo aprendizado e maior tempo de transição.

Na transmissão intercultural se configura, normalmente, uma hierarquização de práticas culturais como uma melhor do que outra para satisfazer alguns valores ou padrões como produtividade, eficiência ou competitividade. Dessa maneira, para alguns, a alteração profícua de seus valores atuais por outros mais promissores - para si próprios e para sua sociedade - facilita o sentido de aderência. Para outros indivíduos, essa inserção pode ser julgada negativa e aguçar um sentimento de resistência. Na incorporação de práticas gerenciais inusitadas há julgamentos de valor sobre o melhor e o pior e a expectativa das pessoas em relação a novidades. Portanto, há duplos sentimentos, de aderência ou resistência, de acordo com as visões individuais de progresso.

O importante a ressaltar são as escolhas conscientes das pessoas. Existe uma margem individual psicológica não explicável pela programação cultural coletiva para definir formas de aderência e de resistência. Por essa razão, muitas empresas e entidades são bem-sucedidas em muitos contextos internacionalmente diversificados, apesar de desconhecer as advertências de conflitos culturais.

\section{A ênfase na contaminação cultural pode desvalorizar a possibilidade de aprendizado e desenvolvimento além dos próprios criadores}

As culturas produtoras de conhecimentos gerenciais, de países mais avançados, aparecem naturalmente como mais eficientes e merecedoras de inspiração e utilidade. Gestores presumem ser suas organizações ainda não 
igualmente capazes, não necessariamente por inferioridade cultural, mas por depender de um passo adicional: a inserção adaptativa de novos conhecimentos.

A assimilação de padrões gerenciais inusitados por uma cultura de acolhimento é claramente notável na realidade cultural contemporânea. A absorção de uma nova cultura gerencial é, de certa forma, mais forte que o inverso (PARKER, 1998; 2000). Nesse sentido, há proposições sobre a nova amplitude de conceitos, significando mais universalização, para o desempenho de gerentes internacionais (BODDEWYN, TOYNE, MARTINEZ et al., 2004), bem como de novas teorias de maior alcance (CHENG, GUO e SKOUSEN, 2011).

Ideias gerenciais são praticadas com êxito em empresas e entidades internacionais que atuam em vários países, mas são igualmente recusadas ou mal aplicadas em outras empresas, de iguais dimensões e nos mesmos países. Não é por indiferença ou desconsideração inadvertida que essas organizações, ou mesmo escolas de gestão, aplicam-se mais à prática e à transmissão de novos conceitos gerenciais.

Principalmente as grandes empresas, de classe mundial, têm uma consciência aguçada sobre dimensões de competitividade, custo e eficiência: veem os novos conhecimentos gerenciais como um fator mais decisivo a ser aplicado universalmente. Gerentes bem-sucedidos não o são por guardar os valores centrais de sua cultura, mas por ter incorporado os valores gerenciais mais propagados e dominantes.

A globalização também cria culturas de produção tão imensamente variadas quanto as de acolhimento. Hoje, o espaço geográfico cultural é um lugar simultâneo de produção, exportação e acolhimento. A gerência moderna é uma forma avançada de organizar o mosaico cultural que invade a produção e a prestação de serviços. Culturas convivem e interagem com mais intensidade e frequência, notadamente porque a sobrevivência contemporânea dos povos exige a ampliação das interações.

\section{Há uma maior atenção a fatores universais para explicar o desempenho organizacional}

Já se concede atualmente uma maior importância a fatores de caráter universal para explicar o desempenho organizacional. Isso significa, comparativamente, uma redução das perspectivas explicativas de práticas gerenciais com base na cultura nacional.

As pesquisas do grande projeto denominado Globe (HOUSE, HANGES, JAVIDAN et al., 2004) ressaltam comunalidades na área gerencial e os avanços na identificação de clusters - isto é, o agrupamento de culturas nacionais por similaridades. Verifica-se que entre clusters diferentes há muitas semelhanças em fatores gerenciais. $\mathrm{Na}$ área de liderança, por exemplo, há fatores comuns como facilitadores e impedimentos universais (HOUSE, HANGES, JAVIDAN et al., 2004).

Empresas e organizações internacionais tendem a trabalhar segundo fórmulas gerenciais comuns. Notam-se a influência externa e a perda de algumas tradições, mas se relatam fatores motivacionais comuns, como renda e progresso individual (BERGER e HUNTINGTON, 2002). Além disso, gerentes são mais propensos a assimilar e responder positivamente a valores de suas organizações, independente de outros fatores culturais (OGBONNA e WILKINSON, 2003).

Mudanças no comportamento gerencial são mais em função de supervisão e controle diretos ou ameaça de sanções do que de qualquer transformação de valores culturais. Assim, gerentes internacionais, trabalhando em vários países, tendem a pôr em prática as mesmas atitudes e comportamentos gerenciais a que estavam acostumados anteriormente, em outros espaços culturais (OGBONNA e WILKINSON, 2003).

Por outro lado, já se mostrou ser baixa a associação entre cultura nacional e desempenho, sobretudo no setor industrial. Condições da indústria influenciam processos culturais. O êxito de uma mudança cultural depende 
do setor econômico no qual é introduzida (OGBONNA e HARRIS, 2002; ABRAHANSON e FOMBRUM, 1994; CHRISTENSEN e GORDON, 1999; MEYERSON e MARTIN, 1987).

O empreendedorismo, promovido pela imigração, inclusive o oriundo de países em desenvolvimento, é cada vez mais reconhecido como um fator importante para o crescimento econômico (ASSUDANI, 2009). Os países em desenvolvimento, com maiores índices de crescimento, possuem mais facilidades e incentivos ao empreendedorismo (DANIS, DE CLERQ e PETRICEVIC, 2011).

No entanto, vale notar, pessoas com espírito empreendedor, em diferentes países, possuem as mesmas características não só em contraste com outros funcionários, mas independente de fatores culturais (MCGRATH, MACMILLAN, YANG et al., 1992; THOMAS e MUELLER, 2000; OHE, HONJO, OLIVA et al., 1991; HOLT, 1997; ARDICHIVILLI e GASPARISHVILLI, 2003). Assim, o espírito empreendedor aparece claramente como uma dimensão de universalidade, apesar de ser um dos fatores da cultura ocidental mais associados ao individualismo.

\section{A transmissibilidade do conhecimento é um processo adaptativo e criativo}

Pelas imposições da globalização, as organizações se tornam mais atentas, hábeis e ativas para identificar em seu ambiente externo os conhecimentos e as práticas que julgam lhes ser os mais úteis. A procura de novas ideias já significa uma seletividade e um julgamento sobre suas possibilidades e sua relevância.

A transposição de conhecimentos se faz por meio de um processo adaptativo e criativo de inserção de novas dimensões gerenciais.

A transferência cultural não é uma mera reprodução do conhecimento: exige uma adaptação, inclusive de natureza não cultural. Há sempre uma modificação, sobretudo no receptor. Dessa forma, não há uma divisão rígida entre culturas produtoras e receptoras, pois a transferência de conhecimentos também é uma ação criativa, ou produtora.

Tanto a cultura receptora quanto a produtora necessitam reconhecer o valor e a utilidade do conhecimento a ser transferido (EASTERBY-SMITH, LYLES e TSANG, 2008; GUPTA e GOVINDARAJAN, 1991; 2000). No entanto, o êxito da transferência depende menos do produtor original e mais do valor atribuído ao conhecimento pela cultura receptora (WILKESMANN, FISCHER e WILKESMANN, 2009).

Na prática gerencial, por ser, de início, a cultura detentora do conhecimento, de suas potencialidades e de evidências sobre seu valor prático, a perspectiva do produtor tende a ser ressaltada. Mas há um estoque de conhecimentos no ambiente local de recepção (GHOSHAL, 1987) capaz de identificar a relevância e facilitar o uso do novo saber.

A transmissibilidade depende da capacidade potencial do receptor para usufruir o novo saber (ZAHRA e GEORGE, 2002; VAN WIJK, JANSEN e LYLES, 2008). Na verdade, quanto maior o estoque de conhecimentos na organização receptora, maior o aproveitamento de novas ideias.

A habilidade de reconhecer, assimilar e aplicar novos conhecimentos depende do saber previamente acumulado (COHEN e LEVINTHAL, 1990). Portanto, se a transferência também é uma produção e um aprendizado mútuo, não se pode alienar a cultura receptora de um papel efetivo na sua absorção.

Atualmente, a perspectiva da transmissibilidade é reforçada pela própria construção das teorias e práticas gerenciais em um mundo culturalmente mais globalizado. A distinção entre culturas, produtoras e receptoras, já parece minimizada. 
Por se julgar haver nas teorias contemporâneas uma excessiva incorporação de perspectivas de outras disciplinas e, também, uma base intercultural preestabelecida, propõe-se, como alternativa à busca de teorias de fora, um processo duplo, para favorecer a maior participação das culturas receptoras em toda formulação teórica (OSWICK, FLEMING e HANLON, 2011).

\section{Considerações Finais}

O progresso da atividade científica e profissional levou a uma nova dinâmica social e à integração entre o conhecimento e a prática gerencial. Anteriormente, a visão de uma sociedade mais passiva e descrente das próprias possibilidades favorecia a dificuldade de receber o inusitado. O novo conhecimento gerencial renovou a dinâmica do desenvolvimento: a importância da capacidade gerencial ficou mais clara para responder às novas demandas sociais e econômicas. Assim, empresas e entidades públicas deram simultaneamente um passo diante, valorizando suas potencialidades.

As organizações modernas conquistam seu progresso por meio de uma adaptação constante às oportunidades e às novas condições culturais. A trilha gerencial significa o percurso do incerto e do desconhecido. As fronteiras do mundo globalizado são mais amplas, abertas e ambíguas, e o conceito de cultura nacional já é menos um obstáculo para avançar nas transações empresariais e mais uma forma de conscientizar-se sobre novas possibilidades de realização.

Por haver uma consciência universal sobre o valor da produção e da disseminação do saber, o mundo moderno aprendeu mais sobre a influência de fatores culturais e a usá-los de forma integrada e efetiva. Conhecimentos produzidos em várias culturas se tornam mais facilmente úteis, compartilhados e valorados por todos. Contatos interculturais são constantes: reativam diariamente um novo aprendizado sobre formas criativas de inter-relacionar-se e criar valores.

A introdução de novos hábitos e métodos administrativos tem a ver menos com o sentimento negativo de falta de conhecimento e mais com a visão positiva de usufruir saberes diferentes capazes de produzir mais satisfação para uma sociedade. Por princípio, não significa alterar valores fundamentais de um grupo social, mas melhorar seus processos de trabalho e suas conquistas humanas. Por isso, a expectativa da melhor gestão para maior produtividade e satisfação social tende a ser comum em praticamente todas as culturas.

A nova perspectiva da transmissibilidade significa, além de uma inovação técnica gerencial, uma descoberta de possibilidades adicionais de criar valor e de contribuir para o progresso. Não se destroem os valores explícitos da cultura produtora nem os ideais da cultura receptora, mas há a integração criativa de práticas e de conhecimentos de ambas as culturas. 


\section{Referências}

ABONYI, G.; VAN SLYKE, D. M. Governing on the edges: Globalization of production and the challenge to public administration in the twenty-first century. Public Administration Review, v. 70, n. special issue, p. 33-45, 2010.

ABRAHANSON, E.; FOMBRUN, C. J. Macrocultures: determinants and consequences. Academy of Management Review, v. 19, n. 4, p. 728-755, 1994.

AILON-SOUDAY, G.; KUNDA, G. The local selves of global workers: the social construction of national identity in the face of organizational globalization. Organization Studies, v. 24, n. 7, p. 1073-1096, 2003.

AITKEN, B. J.; HARRISON, A. E. Do domestic firms benefit from direct foreign investment? Evidence from Venezuela. American Economic Review, v. 89 n. 3, p. 605-618, 1999.

ANTHONY, P. D. The paradox of the management of culture or 'he who leads lost'. Personnel Review, v. 19, n. 4, p. 3-8, 1990.

ARDICHIVILLI, A.; GASPARISHVILLI, A. Russian and Georgian entrepreneurs and non-entrepreneurs: a study of value differences. Organization Studies, v. 24, n. 1, p. 29-46, 2003.

ARGOTE, L.; INGRAM, P. Knowledge transfer: a basis for competitive advantage in firms. Organizational Behavior and Human Decision Processes, v. 82, n. 1, p. 150-169, 2000.

ASSUDANI, R. H. Ethnic entrepreneurship: the distinct role of ties. Journal of Small Business and Entrepreneurship, v. 22, n. 2, p. 197-206, 2009.

BARTLETT, K. R. et al. Differences in international human resource development among indigenous firms and multinational affiliates in East and Southeast Asia. Human Resource Development Quarterly, v. 13, n. 4, p. 383-405, 2002.

BERGER, P. L.; HUNTINGTON, S. P. Many globalizations: cultural diversity in the contemporary world. Oxford: Oxford University Press, 2002.

BJÖRKMAN, I.; FEY, C.; PARK, H. J. Institutional theory and MNC subsidiary HRM practices: evidence from a three-country study. Journal of International Business Studies, v. 38, n. 3, p. 430-446, 2007.

; STAHL, G.; VAARA, E. Impact of cultural differences on capability transfer in acquisitions: the mediating roles of capability complementarity, absorptive capacity, and social integration. Journal of International Business Studies, v. 38, n. 4, p. 658-672, 2007.

BLOOM, N.; VAN REENEN, J. Measuring and explaining management practices across firms and countries. Quarterly Journal of Economics, v. 122, n. 2, p. 1351-1408, 2007.

BODDEWYN, J. J.; TOYNE, B.; MARTINEZ, Z. L.The meanings of "international management". Management International Review, v. 44, n. 2, p. 195-212, 2004.

BOYLE, R. P.; COUGHLIN, R. M. Conceptualizing and operationalizing cultural theory. In: COYLE, D.; ELLIS, R. J. Politics, policy and culture. Boulder: Westview Press, 1994.

BRESMAN, H.; BIRKINSHAW, J.; NOBEL, R. Knowledge transfer in international acquisitions. Journal of International Business Studies, v. 30, n. 3, p. 439-463, 1999.

BROX, J.; FADER, C. The set of just-in-time management strategies: an assessment of their impact on plant-level productivity and input-factor substitutability using variable cost function estimates. International Journal of Production Research, v. 40, n. 12, p. 2705-2720, 2002.

BUCKLEY, P. J.; CARTER, M. Managing cross-border complementary knowledge. International Studies of 
Management and Organization, v. 29, n. 1, p. 80-104, 1999.

; CLEGG, J.; WANG, C. The impact of inward FDI on the performance of Chinese manufacturing firms. Journal of International Business Studies, v. 33, n. 4, p. 637-655, 2002.

BUONO, A. F.; BOWDITCH, J. L. The human side of mergers and acquisitions. San Francisco: Jossey-Bass, 1989.

CHENG, J. L. C.; GUO, W.; SKOUSEN, B. Advancing new theory development in the field. Management International Review, v. 51, n. 6, p. 787-802, 2011.

CHILD, J.; FAULKNER, D.; PITKETHLY, R. Foreign direct investment in the UK 1985-1994: the impact on domestic management practice. Journal of Management Studies, v. 37, n. 1, p. 141-166, 2000.

CHRISTENSEN, E. W.; GORDON, G. An exploration of industry culture and revenue growth. Organization Studies, v. 20 , n. 3, p. 397-422, 1999.

COHEN, W. M.; LEVINTHAL, D. A. Absorptive capacity: a new perspective on learning and innovation. Administrative Science Quarterly, v. 35, n. 1 p. 128-152, 1990.

CORNELISSEN, J. P.; HASLAM, S. A.; BALMER, J. M. T. Social identity, organizational identity, and corporate identity: towards an integrated understanding of processes, patternings, and products. British Journal of Management, v. 18, n. Supplement 1, p. 1-16, 2007.

COYLE, D.; ELLIS, R. J. Politics, policy and culture. Boulder: Westview Press, 1994.

DAMERON, S.; JOFFRE, O. Management d'une équipe européenne: difficultés relationnelles et construction identitaire. In: HALIKA, M. Management européen et mondialisation. Paris: Dunod, 2005.

DANIS, W. M.; DE CLERCQ, D.; PETRICEVIC, O. Are social networks more important for new business activity in emerging than developed economies? An empirical extension. International Business Review, v. 20, n. 4, p. 394-408, 2011.

DOUGLAS, M. Natural symbols: exploration in cosmology. London: Barrie \& Rocliff, 1970.

Risk and blame: essays in cultural theory. London: Routhledge, 1992.

DUANMUI, J.; FAI, F. M. A processual analysis of knowledge transfer: from foreign MNEs to Chinese suppliers. International Business Review, v. 16, n. 4, p. 449-473, 2007.

EASTERBY-SMITH, M.; LYLES, M. A.; TSANG, E. W. K. Inter-organizational knowledge transfer: current themes and future prospects. Journal of Management Studies, v. 45, n. 4, p. 677-690, 2008.

EMPSON, L. Fear of exploitation and fear of contamination: impediments to knowledge transfer in mergers between professional service firms. Human Relations, v. 54, n. 7, p. 839-863, 2001.

FARAZMAND, A. Building administrative capacity for the age of rapid globalization: a modest prescription for the twenty-first century. Public Administration Review, v. 69, n. 6, p. 1008-1020, 2009.

FU, X. Foreign direct investment and managerial knowledge spillovers through the diffusion of management practices. Journal of Management Studies, v. 49, n. 5, p. 970-999, 2012.

GAMBLE, J. Transferring human resource practices from the United Kingdom to China: the limits and potential for convergence. International Journal of Human Resource Management, v. 14, n. 3, p. 369-387, 2003.

Transferring organizational practices and the dynamics of hybridization: Japanese retail multinationals in China. Journal of Management Studies, v. 47, n. 4, p. 705-732, 2010.

GEOFFEROY, C. Managers: quel anglais parlez-vous? In: HALIKA, M. Management européen et mondialisation. 
Paris: Dunod, 2005.

GERHART, B. How Much Does National Culture Constrain Organizational Culture? Management and Organization Review, v 5, n. 2, 241-259, 2009.

Cross cultural management research assumptions, evidence, and suggested directions. International Journal of Cross Cultural Management, v. 8, n. 3, p. 259-274, 2012.

; FANG, M. National culture and human resource management: assumptions and evidence. International Journal of Human Resource Management, v. 16, n. 6, p. 975-990, 2005.

GOSHAL, S. Global Strategy: An Organizing Framework. Strategic Management Journal, v. 8. n. 5, p. 425-440, 1987.

GULRAJANI, N.; MOLONEY, K. Globalizing public administration: today's research and tomorrow’s agenda. Public Administration Review, v. 72, n. 1, p. 78-86, 2012.

GUPTA, A. K; GOVINDARAJAN, V. Knowledge flows and the structure of control within multinational corporations. Academy of Management Review, v. 16, n. 4, p. 768-792, 1991.

$473-496,2000$.

Knowledge flows within multinational corporations. Strategic Management Journal, v. 21, n. 4, p.

HAMEL, G.; PRAHALAD, C. K. Corporate imagination and expeditionary marketing. Harvard Business Review, v. 69, n. 4, p. 81-92, 1991.

. Competindo pelo futuro. Rio de Janeiro: Campos, 2005.

HAMPDEN-TURNER, C.; TROMPENAARS, F. Riding The Waves of Culture: Understanding Diversity in Global Business. New York: McGraw-Hill, 1997.

HARZING, A. W. K. Of bears, bumble-bees, and spiders: the role of expatriates in controlling foreign subsidiaries. Journal of World Business, v. 36, n. 4, p. 366-379, 2001.

HENDRIKS, P. Why share knowledge? The influence of ICT on the motivation for knowledge sharing. Knowledge and Process Management, v. 6, n. 4, p. 91-100, 1999.

HOFSTEDE, G. Culture's consequences: international differences in work-related values. Beverly Hills: Sage, 1980.

. The cultural relativity of organizational practices and theories. Journal of International Business Studies, v. 14, n. 2, p. 75-89, 1983.

Cultures and organizations: software of the mind. London: McGraw-Hill, 1991. Hill, 2010.

; HOFSTEDE, G. J.; MINKOV, M. Cultures and organizations: software of the mind. New York: McGraw-

HOGG, M. A.; TERRY, D. J. Social identity processes in organizational contexts. Philadelphia: Psychology Press, 2001.

HOLDEN, N. J. Cross-cultural management: a knowledge management perspective. London: Financial Times/Prentice Hall, 2002.

HOLDEN, R. Managing people's values and perceptions in multi-cultural organizations: the experience of an HR director. Employee Relations, v. 23, n. 6, p. 614-626, 2001.

HOLT, D. A comparative study of values among Chinese and US entrepreneurs: pragmatic convergence between contracting cultures. Journal of Business Venturing, v. 12, n. 6, p. 483-506, 1997. 
HOUSE, R. J. et al. Culture, leadership and organizations: the Globe study of 62 societies. Thousand Oaks: Sage, 2004.

HUBER, G. P. Organizational learning the contributing processes and the literatures. Organization Science, v. 2, n. 1, p. 88-115, 1991.

Transfer of knowledge in knowledge management systems: unexplored issues and suggested studies.

European Journal of Information Systems, v. 10 n. 1 p. 72-79, 2001.

HUNTER, J. D.; YATES, J. The world of American globalizers. In: BERGER, P. L.; HUNTINGTON, S. P. Many globalizations: cultural diversity in the contemporary world. Oxford: Oxford University Press, 2002.

HUSELID, M. A. The impact of human resources management practices on turnover, productivity and corporate financial performance. Academy of Management Journal, v. 38, n. 3, p. 635-672, 1995.

IBARRA-COLADO, E. Critical Approaches to Comparative Studies in Organizations: From Current Management Knowledge to Emerging Agendas. Canadian Journal of Administrative Sciences v. 28, n 2, p. 154-159, 2011.

JAVIDAN, M. et al. Cross-border transfer of knowledge: cultural lessons from project Globe. Academy of Management Executive, v. 19, n. 2, p. 59-76, 2005.

JEHN, K. A qualitative analysis of conflict types and dimensions in organizational groups. Administrative Science Quarterly, v. 40, n. 3, p. 530-557, 1997.

JREISAT, J. Globalism and comparative public administration. Boca Raton: CRC Press, 2011.

KIRKMAN, B. L.; LOWE, K. B.; GIBSON, C. B. A quarter century of Culture's consequences: a review of empirical research incorporating Hofstede's cultural values framework. Journal of International Business Studies, v. 37, n. 3, p. 285-320, 2006.

KNIGHTS, D.; WILLMOTT, H. Organizational culture as management strategy: a critique and illustration from the financial services industry. International Studies of Management and Organization, v. 17, n. 3, p. 40-63, 1987.

LEGGE, K. Managing culture: fact or fiction. In: BACK, S.; SISSON, K. Personnel management: a comprehensive guide to theory and practice in Britain. Oxford: Blackwell, 1994.

LIU, C. L. Knowledge mobility in cross-border buyer-supplier relationships. Management International Review, v. 52, n. 2, p. 275-291, 2012.

MCADAM, R.; MCCREEDY, S. The process of knowledge management within organizations: a critical assessment of both theory and practice. Knowledge and Process Management, v. 6, n. 2, p. 101-113, 1999.

MCGRATH, R. et al. Does culture endure, or is it malleable? Issues for entrepreneurial economic development. Journal of Business Venturing, v. 7, n. 6, p. 441-458, 1992.

MEYERSON, D.; MARTIN, J. Cultural change: an integration of three different views. Journal of Management Studies, v. 24, n. 6, p. 623-647, 1987.

MINBAEVA, D. et al. 'MNC knowledge transfer, subsidiary absorptive capacity, and HRM. Journal of International Business Studies, v. 34, n. 6, p. 589-599, 2003.

MORAN, R.; HARRIS, P.; MORAN, S. Managing cultural differences: global leadership strategies for cross-cultural business success. Oxford: Butterworth-Heinemann, 2010.

NELSON, R.; GOPALAN, S. Do organizational cultures replicate national cultures? Isomorphism, rejection and reciprocal opposition in corporate values of three countries. Organization Studies, v. 24, n. 7, p. 1115-1151, 2003.

NONAKA, I. Managing organizational knowledge: theoretical and methodological foundations. In: HITT, M. A.; 
SMITH, K. G. (Coord.). Great minds in management. Oxford: Oxford University Press, 2007.

; TAKEUCHI, H. The knowledge creating company. Oxford University Press, Oxford, 1995.

;___ Criação de conhecimento na empresa. Rio de Janeiro: Campus, 2008.

OGBONNA, E.; HARRIS, L. C. Organizational culture: a ten year two-phase study of change in the UK food retailing sector. Journal of Management Studies, v. 39, n. 5, p. 673-706, 2002.

; WILKINSON, B. The false premise of organizational change: a case study of middle managers in grocery retailing. Journal of Management Studies, v. 40, n. 5, p. 1151-1178, 2003.

OGBOR J. O. Critical theory and the hegemony of corporate culture. Journal of Organizational Change Management, v.14, n. 6, p. 590-608, 2001.

OHE, T. et al. A study of perceived differences. Journal of Business Ventures, v. 6, n. 2, p. 135-144, 1991.

OSWICK, C.; FLEMING, P.; HANLON, G. From borrowing to blending: rethinking the processes of organizational theory building. Academy of Management Review, v. 36, n. 2, p. 318-337, 2011.

PARKER, M. Organization, community and utopia, studies in cultures. Organizations and Societies, v. 4, n. 1, p. 7191, 1998.

Organizational culture and identity. London: Sage, 2000.

SANTOSH, B.; MUTHIAH, K. Knowledge transfer from repatriated employees: the Indian experience. The IUP Journal of Knowledge Management, v. 10, n. 1, p. 7-25, 2012.

SCHAFFER, B. S.; RIORDAN, C. M. A review of cross-cultural methodologies for organizational research: a bestpractices approach. Organizational Research Methods, v. 6, n. 2, p. 169-215, 2003.

SIMONIN, B. L. Transfer in marketing know-how in international strategic alliances: an empirical investigation of the role of antecedents of knowledge ambiguity. Journal of International Business Studies, v. 30, n. 3, p. 463-490, 1999.

SIRMON, D. G.; LANE, P. J.A model of cultural differences and international alliance performance. Journal of International Business Studies, v. 35, n. 4, p. 306-319, 2004.

SWANN JR., W. et al. Finding value in diversity: verification of personal and social self-views in diverse groups. Academy of Management Review, v. 29, n. 1, p. 9-27, 2004.

SZULANSKI, G. Exploring internal stickiness: impediments to the transfer of best practice within the firm. Strategic Management Journal, v. 17, n. special issue 2, p. 27-43, 1996.

TERRY, D. J. Intergroup relations and organizational mergers. In: HOGG, M. A.; TERRY, D. J. (Eds.). Social identity processes in organizational contexts. Philadelphia: Psychology Press, 2001. 249-264 p.

THOMAS, A.; MUELLER, S. A case of comparative entrepreneurship: assessing the relevance of culture. Journal of International Business Studies, v. 31, n. 2, p. 287-302, 2000.

THOMAS, D. Essentials of international management: a cross cultural perspective. Thousand Oaks: Sage, 2002.

TIPTON, F. B. Modeling national identities and cultural change: the Western European, Japanese, and United States experiences compared. International Journal of Cross Cultural Management, v. 9, n. 2, p. 145-168, 2009.

VAN KNIPPENBERG, D.; VAN LEEUWEN, E. 'Organizational identity after a merger: sense of continuity as the key to post-merger identification’ em Hogg, M. A. e Terry, D. J. (Coord.). Social Identity Processes in Organizational Contexts. Philadelphia: Psychology Press, 2001. 
VAN WIJK, R.; JANSEN, J. P.; LYLES, M. Inter- and intra-organizational knowledge transfer: a meta-analytic review and assessment of its antecedents and consequences. Journal of Management Studies, v. 45, n. 4, p. 830-853, 2008.

WANG, J.; LIU, X.; LI, X. A dual-role typology of multinational subsidiaries. International Business Review, v. 18, n. 6 , p. 578-591, 2009.

WATSON, T. J. Organizing and managing work. Harlow: Pearson, 2001.

WIERZBICKA, A. Cross-cultural pragmatics: the semantics of human interaction. Berlin/New York: Mouton de Gruyter, 2003.

WILDAVSKY, A. Choosing preferences by constructing institutions: a cultural theory of preference formation. American Political Science Review, v. 81, n. 1, p. 3-21, 1987.

WILKESMANN, U.; FISCHER, H.; WILKESMANN, M. Cultural characteristics of knowledge transfer. Journal of Knowledge Management, v. 13, n. 6, p. 464-477, 2009.

WILLMOTT, H. Strength is ignorance, slavery is freedom: managing culture in modern organizations. Journal of Management Studies, v. 30, n. 4, p. 515-551, 1993.

YEGANEH, H.; SU, Z. Conceptual foundations of cultural management research. International Journal of Cross Cultural Management, v. 6, n. 3, p. 361-376, 2006.

ZAHRA, S. A.; GEORGE, G. Absorptive capacity: a review, reconceptualization, and extension. Academy of Management Review, v. 27, n. 2, p. 185-203, 2002.

ZANDER, U. Exploiting a technological edge: voluntary and involuntary dissemination of technology. Stockholm: Institute of International Business, 1991.

ZHANG, M. Crossing the river by touching stones: a comparative study of administrative reforms in China and the United States. Public Administration Review, v. 69, n. suppl. 1, p. 582-587, 2009. 